\section{Sero-survey of Hepatitis B surface antigen amongst pregnant women attending Infectious Disease Hospital Bayara, Bauchi State, Nigeria}

\author{
James A. Ndako, 1 \\ Georgebest ON. Echeonwu, ${ }^{1}$ \\ Obinna O Nwankiti, ${ }^{2}$ \\ Emamuzou M. Onovoh, ${ }^{1}$ \\ Alloysius U. Jah, ${ }^{1}$ \\ Nathaniel N. Shidali, ${ }^{4}$ Patrick A. Ikani ${ }^{3}$ \\ 'Department of Virology, Federal College \\ of Veterinary and Medical Laboratory \\ Technology, Vom; ${ }^{2}$ National Veterinary \\ Research Institute, Vom; ${ }^{3}$ Department of \\ Laboratory Services, Family Health \\ International, Bauchi; ${ }^{4}$ Department of \\ Medical Laboratory Sciences, University \\ of Maiduguri, Nigeria
}

\section{Abstract}

Hepatitis B virus (HBV) continues to cause serious health problems in developing countries. Neonatal infection with HBV, which is often acquired during delivery, carries a high risk resulting in persistent infection. This research aims to detect the prevalence of Hepatitis B surface Antigen (HBsAg) among pregnant women in our location of study. One hundred and eighty (180) sera samples were screened among pregnant women aged 13-49, using standard enzyme-linked immunosorbent assay (ELISA) method. Structured questionnaire were administered to the subjects to obtain demographic and other relevant data. Overall result showed that $31(17.2 \%)$ were found to be positive for HBsAg among the total subjects screened. The highest prevalence was found among those aged 20-29 with 11 (6.1\%) seropositivity $\left(\chi^{2}=7.902 ; \mathrm{P}=0.048\right)$. Conside ring occupational distribution of volunteer subjects, a high prevalence of 12 (6.7\%); $\mathrm{P}<0.05$ was recorded among house wives, which shows a measure of significance compared to other women screened. Furthermore, based on various risk factors subjects with history of surgery and use of unsterilized sharp instruments recorded 15 (8.3\%) prevalence $(\mathrm{P}=0.233 ; \mathrm{P}>0.05)$. However, women in their second trimester of pregnancy recorded a higher prevalence of 23 (12.8\%):( $\mathrm{P}=0.080$; $\mathrm{P}<0.05)$. This study therefore emphasizes the public health importance of HBV among pregnant women and equally suggests that children born to women with Hepatitis B Virus, be closely monitored for infection beyond the one and the half years of age, this also calls for a proper enlightenment on the dangers posed by the virus, while a well designed vaccination schedule is advocated among the general population.

\section{Introduction}

Hepatitis B virus (HBV) occurs worldwide and constitutes a serious public health problem. Globally, it is estimated that more than 2 billion people have been infected with HBV; of these, about 350 million developed chronic infection and became carriers of the virus, while about 1.5 million deaths occurred from $\mathrm{HBV}$ related liver diseases, including end stage cirrhosis and hepatocellular carcinoma each year. ${ }^{1,2} \mathrm{HBV}$ infection is spread through three major routes: perinatal, horizontal, and sexual transmission. ${ }^{3}$ In developing countries, the main routes of transmission are: neonatal with HBV carrier mother infecting her infant usually during birth or soon after birth following close contact, transmission of HBV via cuts, from reuse of unsterile sharp objects, sexual transmission, transfusion of infected blood or blood products, needle stick injury, re-use of HBV contaminated needles, syringes, lancets and instruments including those used in tribal body markings. ${ }^{2}$ Neonates who contract Hepatitis will have almost the a $90 \%$ risk of

Table 1. Distribution of hepatitis B surface antigen within the population screened.

\begin{tabular}{lccc} 
Location & Positive (\%) & Negative (\%) & Total (\%) \\
Infectious Disease Hospital Bayara & $31(17.2)$ & $149(82.8)$ & $180(100)$ \\
\hline
\end{tabular}

Table 2. Distribution based on age group hepatitis B surface antigen status.

\begin{tabular}{lccc} 
Age group & Positive (\%) & Negative (\%) & Total tested \\
$10-19$ & $7(3.9)$ & $25(13.9)$ & 32 \\
$20-29$ & $11(6.1)$ & $75(41.7)$ & 86 \\
\hline $30-39$ & $8(4.4)$ & $43(23.9)$ & 51 \\
$40-49$ & $5(2.8)$ & $6(3.3)$ & 11 \\
\hline Total & $31(17.2)$ & $149(82.8)$ & 180 \\
\hline
\end{tabular}

$\chi^{2}=7.902 ; \mathrm{df}=3 ; \mathrm{P}=0.048$

Table 3. Distribution of Hepatitis B virus based on demographic factors.

\begin{tabular}{lcccc} 
Occupation & No. Tested & Positive (\%) & Negative (\%) & P value \\
Housewives & 106 & $12(6.7)$ & $94(52.2)$ & 0.004 \\
Traders & 23 & $8(4.4)$ & $15(8.3)$ & 0.004 \\
\hline Civil Servants & 14 & $9(5.0)$ & $5(2.8)$ & 0.004 \\
Farmers & 37 & $2(1.1)$ & $35(19.4)$ & 0.371 \\
\hline Total & 180 & $31(17.2)$ & $149(82.8)$ & \\
\hline
\end{tabular}

Correspondence: James A. Ndako, Federal College of Veterinary and Medical Laboratory Technology, PMB 01, Vom Plateau State, Nigeria. Tel: +2347038540403 .

E-mail: ndakoj@yahoo.co.uk

Key words: Hepatitis B, pregnant women, antenatal.

Received for publication: 14 October 2011.

Accepted for publication: 23 December 2012.

work is licensed under a Creative Commons Attribution NonCommercial 3.0 License (CC BY-

(C)Copyright J.A. Ndako et al., 2012

Licensee PAGEPress, Italy

Microbiology Research 2012; 3:e10

developing chronic HBsAg carriage and chronic liver disease. Infants may also spread the disease to siblings and to a community ${ }^{4}$ about $80-90 \%$ of chronic infections have been found amongst infected neonates born to HBAg positive carrier mothers, followed by children unin-months of age (30\%) Currently about 18 million Nigerians are infected. Many of these people may not be 
aware of the infection and hence fail to seek appropriate medical attention.

There is a common belief that transmission of Hepatitis B virus from carrier mothers to their babies can occur during the prenatal period. Vertical transmission from infected mother to infant is thought to be partially responsible for high prevalent of infection in certain among high risk group individuals. ${ }^{5}$ Hence it is recommended that high risk pregnant women should be tested for hepatitis B surface antigen (HBsAg) early in each pregnancy. ${ }^{6}$

The aim of this paper is to ascertain the prevalence of Hepatitis B surface Antigen among pregnant women in Bayara-Bauchi metropolis and to determine the possible risk it poses to foetus at birth, as this will help the identification of newborns who will require prophylaxis against perinatal infection (infants born to mothers positive for hepatitis B surface antigen have a $70-90 \%$ chance of acquiring perinatal HBV infection). Hence the in-utero transmission of $\mathrm{HBV}$ from infected mother to their off spring has been well documented.

\section{Materials and Methods}

This study was carried out at the Infectious

Table 4. Distribution based on risk factors.

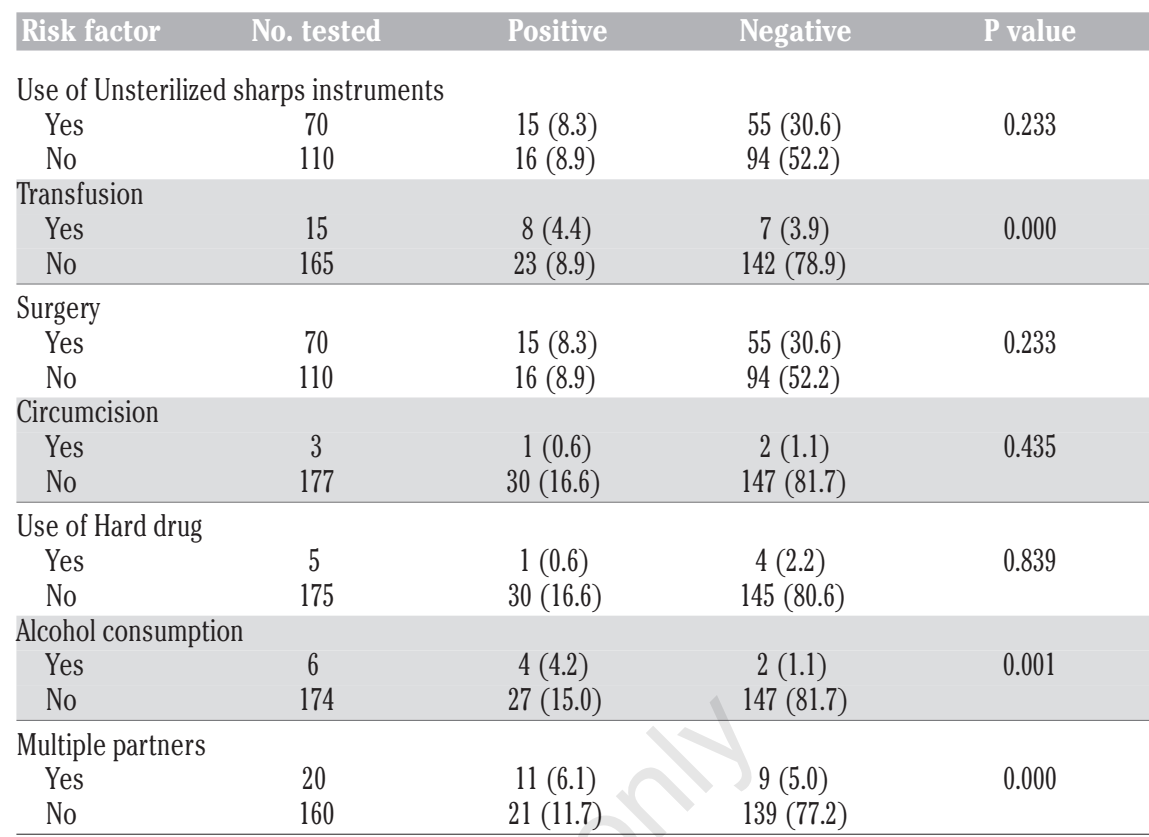

Table 5. Distribution based on trimesters.

\begin{tabular}{lcccc} 
Gestational & Trimester & Positive (\%) & Negative (\%) & Total \\
age in weeks & No Tested & & $33(18.3)$ & 0.080 \\
First trimester & 36 & $3(1.7)$ & $86(14.8)$ & 0.080 \\
Second trimester & 109 & $23(12.8)$ & $30(16.7)$ & 0.057 \\
\hline Third trimester & 35 & $5(2.8)$ & &
\end{tabular}

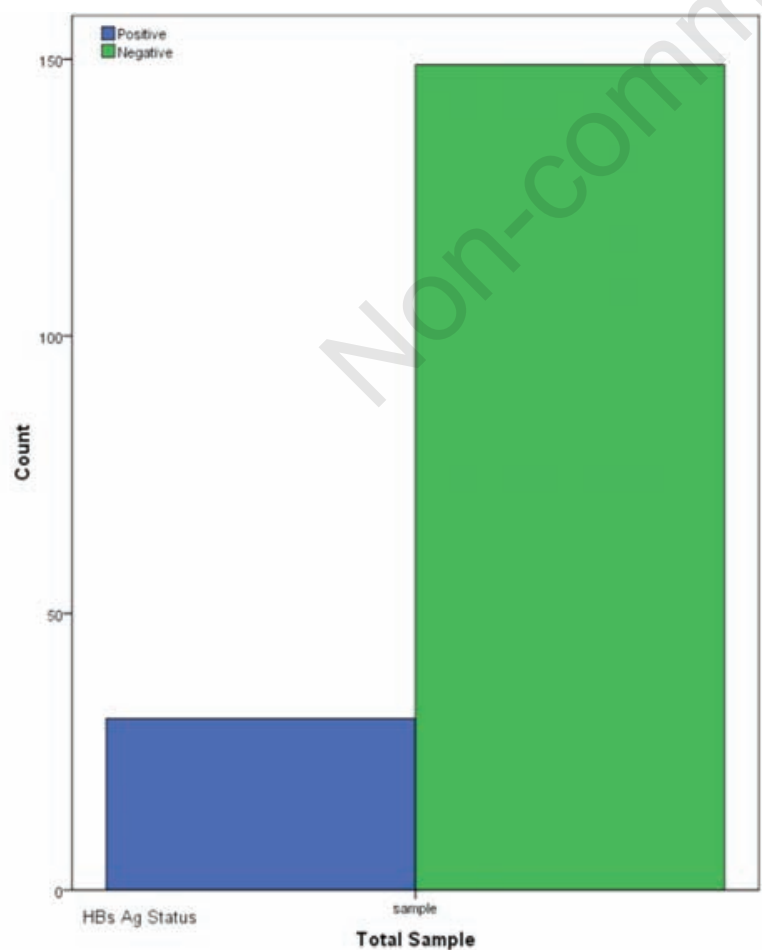

Figure 1. Overall distribution of hepatitis $B$ surface antigen among pregnant women.

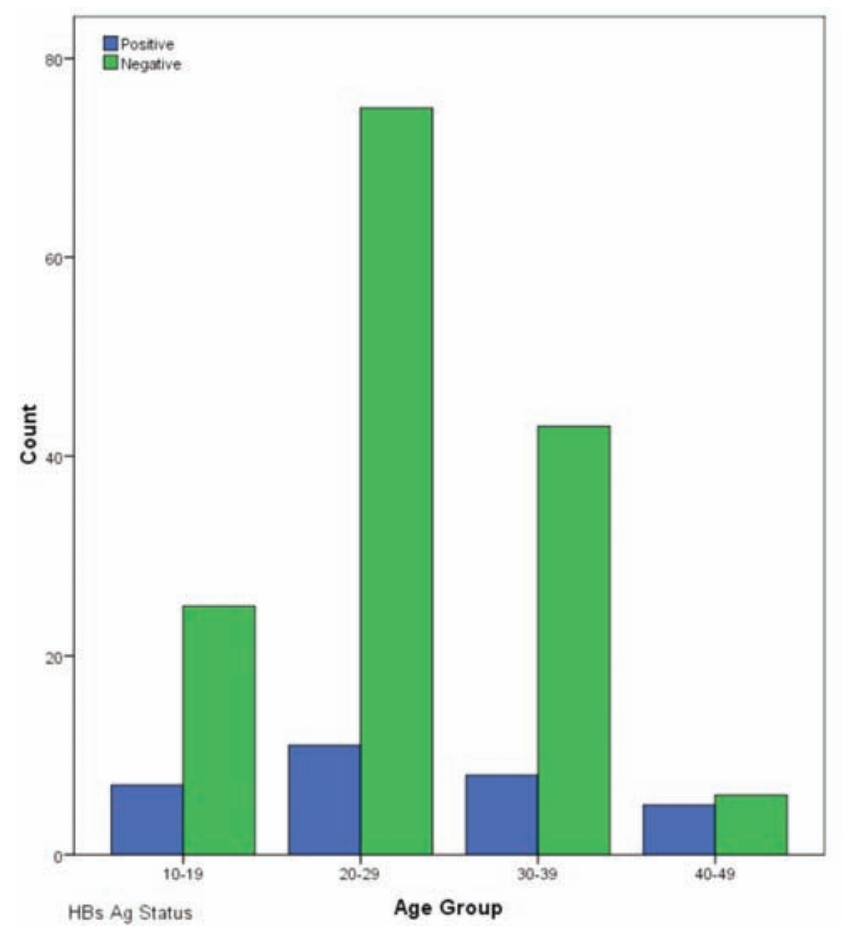

Figure 2. Age distribution as seroprevalence of hepatitis B surface antigen among pregnant women. 
Disease Hospital, Bayara, in Bauchi state, Nigeria. Women attending antenatal clinic at Infectious Disease Hospital, Bayara, were recruited for this study. A well structured questionnaire was issued to these subjects to obtain demographic and other relevant data (Tables 1-5, Figures 1-4). Moreover, 3-5 mL of venous blood were collected, duly labelled and allowed to clot and sera carefully separated into cryovials and stored at $-20^{\circ} \mathrm{C}$ prior use. The materials used include serum, container, hypodermic syringe, cotton wool, micro pipette centrifuge, Hepatitis B surface Antigen ELISA plate, test tube, plate sealer and marker. The reagent used were: Hepatitis B antigen ELISA kit (Kinghawk Beijing Pharmaceutical Co. Ltd) and the Methylated spirit (70\% alcohol). The HBsAg ELISA kit is a double antibody sandwiched ELISA designed to detect HBsAg in human serum or plasma. The anti-HBsAg (monoclonal antibodies) was coated on the solid phase of polystyrene microtitre Elisa wells. Serum sample and the multiclonal antiHBs (conjugated) coated wells were incubated with Tetramethylbenzidine (TMB) to form a colored product or not to indi-cate the presence or absence of HBsAg.Ethical clearance was sought for and obtained before the study commenced.

\section{Discussion}

In this study a prevalence of $17.2 \%$ was recorded. The result obtained is significant if compared with a related study in Maiduguri which showed that prevalence increased from $11.6 \%$ in 1994 to $15.8 \%$ in $1999 .{ }^{7,8}$ Furthermore, the results obtained in this study are equally higher than those obtained by Pennap et al. ${ }^{9}$ who recorded a prevalence of of $6.67 \%$ among pregnant women attending antenatal clinic in Federal Medical Center Keffi, the works by Ndams et al., ${ }^{10}$ recorded $12.3 \%$ prevalence in a study conducted among pregnant women in Minna, and the ones carried out by Onwuliri et al. ${ }^{11}$ where a prevalence of $16.6 \%$ was recorded in a study among pregnant women in Vom.

Lower reports include $2.19 \%$ in Benin City, ${ }^{12}$ $4.3 \%$ in Port Harcourt in $2005,{ }^{13} 2.89 \%$ in $2006,{ }^{14}$ and $5.7 \%$ in Ilorin. ${ }^{15}$ Within the same continent, the result of this study is higher than the $6.3 \%$ reported in pregnant women in Tanzania and $3.7 \%$ in Ethiopia. ${ }^{16}$

The reported prevalence in this study is a cause for alarm because it is high enough to warrant the initiation of routine antenatal screening for HBV infection. This is because
HBV positive pregnant women represent a major reservoir of the virus in a community and this can be passed on to the children either vertically or even horizontally Onwuliri et al. ${ }^{11}$

In this study women aged 20-29 recorded $6.1 \%$ prevalence compared to other age group with the lowest prevalence of $2.8 \%$ recorded among subjects aged 40-49, this is however contrary to the report of Pennap et al. ${ }^{9}$ who recorded a high prevalence of $12.5 \%$ among pregnant women aged 40-44.The resultant high prevalence among this age group in our study is attributed to the fact that these women fall within the sexually active age bracket according to Zali et al. ${ }^{17}$ Age is an important factor in epidemiology studies hence the age of acquiring infection was found to be a major determinant of the incidence of HBV. Most of the women studied were in the $2^{\text {nd }}$ trimester of gestation, this group also had the highest HBsAg seropositivity of $12.8 \%$, the result obtained in this study is lower than those of Ndams et al. ${ }^{10}$ who obtained a prevalence of $13.4 \%$ at the $2^{\text {nd }}$ trimester of pregnancy. Analysis showed that out of the 106 respondents, (58.8\%) were housewives out of which about $12(6.7 \%)$ tested positive for HBsAg as compared to civil servants who recorded $5.0 \%$ positivity, Although $\mathrm{HBV}$

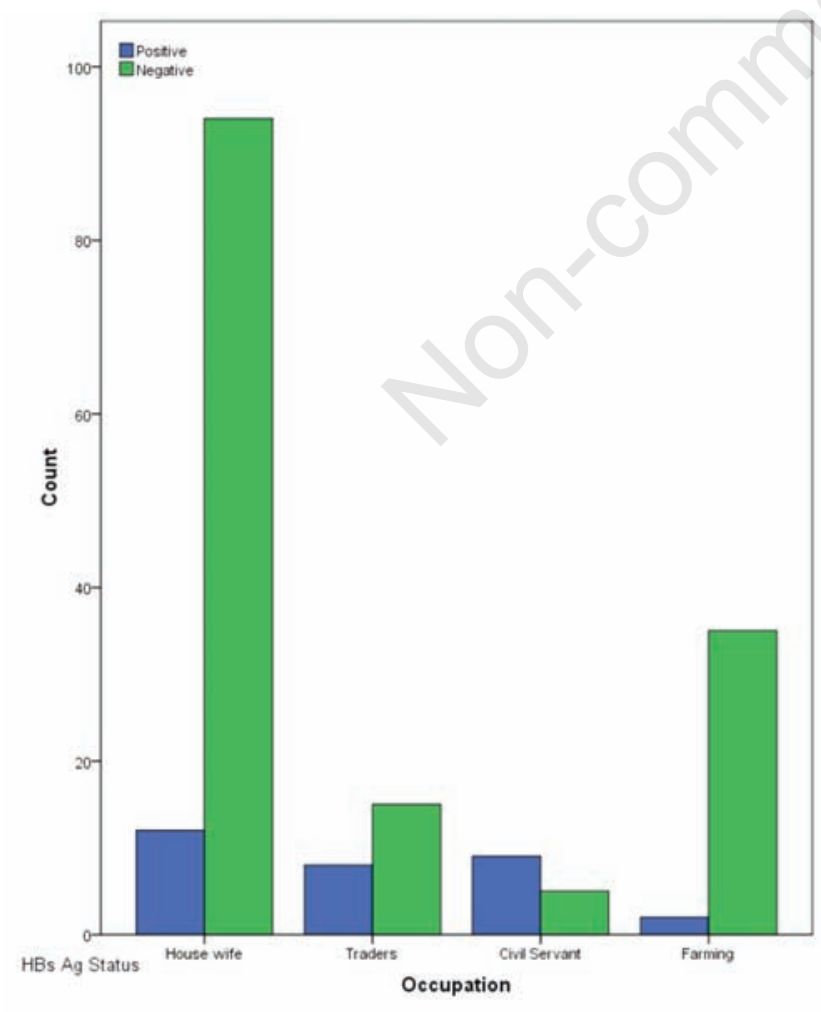

Figure 3. Occupational distribution of hepatitis B surface antigen among pregnant women.

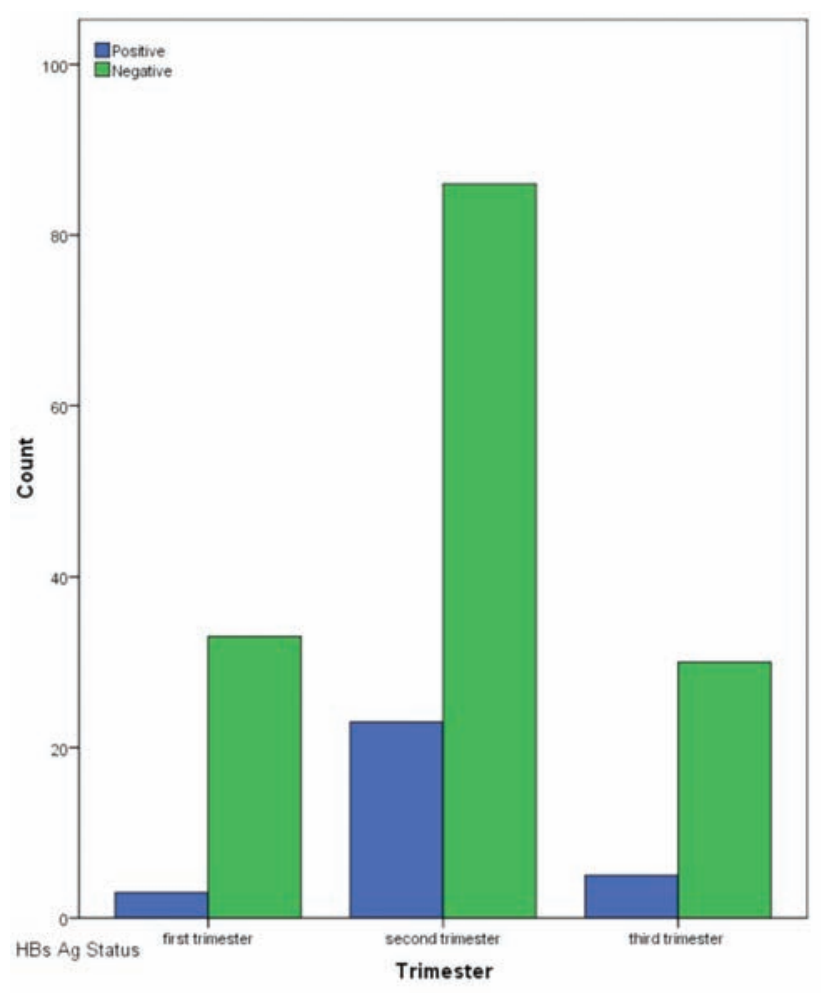

Figure 4. Distribution of hepatitis B surface antigen among pregnant women with respect to trimester. 
infection is considered one of the most important occupational infectious hazards in developed countries ${ }^{18}$ results from this study did reveal statistical but not Clinical significance between HBV Seropositivity and the different occupations of the pregnant women studied. Women with a history of blood transfusions recorded a prevalence of $4.4 \%$, while those with history of surgery recorded $8.3 \%$ similarly those with history of use of unsterilized/sharp instruments also recorded $8.3 \%$ prevalence which was statistically higher than other groups. This implies that the infections in this class of women possibly resulted from wounds obtained from exchange or re-use of sharp instruments. Although WHO recommended that hepatitis B vaccine be incorporated into routine infant and childhood immunization program for all countries by 1997, only 130 of 216 countries introduced hepatitis B immunization into their national infant and childhood immunization programme by the beginning of 2001 . The major hurdle to universal hepatitis B immunization is the cost of hepatitis B vaccine, especially for developing countries the cost of three doses of hepatitis $B$ vaccine remains higher than the cost of other vaccines included in routine infant immunization programmes. ${ }^{19}$

\section{Conclusion}

This study reported a relatively high prevalence of HBsAg in the study area despite the high prevalence all the risk factors studied were not statistically significant as predisposing factors to HBV infection, Thus screening of all pregnant women should be made part of the antenatal care irrespective of risk factors. Likewise the administration of prophylaxis for babies of HBsAg positive mothers will greatly assist in reducing maternal transmission of HBV.

\section{References}

1. Ferriara MS. Diagnosis and treatment of hepatitis B. Rev Soc Bras Med Trop 2000;33:389-400.

2. Cheesbrough M. District laboratory practice in tropical countries, 3rd ed. Cambridge, UK: Cambridge University press; 2000. pp. 250-252

3. Edmunds WJ, Medley GF, Nokes DJ. The transmission dynamics and control of hepatitis B virus in The Gambia. Stat Med 1996;30:2215-33.

4. Sriprakash I, Anil TP. Routine prenatal screening of Indian women for HBsAg: benefits derived versus cost. Trop Doc 1997;27:176-7.

5. Arevalo JA. Hepatitis B virus in pregnancy. WJ Med 1989;150;668-78.

6. Corrarino JE, Walsh PJ, Anselmo D. A program to educate women who test positive for hepatitis $\mathrm{B}$ virus during the prenatal period. MCN Am J Matern Child Nurs 1999:24:73-7.

7. Harry TO, BaJani MD, Moses AE. Hepatitis $B$ virus infection among blood donors and pregnant woman in Maiduguri Nigeria. East Afr Med J 1994;17:32-3.

8. Baba MM, Onwuka IS, Baba SS. Hepatitis $\mathrm{B}$ and $\mathrm{C}$ virus infection among pregnant women in Maiduguri Nigeria. Certr Eur J Publ Hlth 1999;2:60-2.

9. Pennap GR, Osanga ET, Ubam A. Seroprevalence of Hepatitis B surface antigen among pregnant women attending antenatal clinic in Federal Medical Center Keffi, Nigeria. Res J Med Sci 2011;5:80-2.

10. Ndams IS, Joshua IA, Luka SA, Sadiq HO. Epidemiology of Hepatitis B infection among pregnant women in Minna, Nigeria. Sci World J 2008;3:5-8.

11. Onwuliri FC, Ndako JA, Olabode AO, et al. Seroprevalence of Hepatitis B surface antigen (HBsAg) among pregnant women in Vwang District Plateau State Nigeria. Nigerian J Biotechnol Vol.19: pp.60-65 ISSN 0189-1731

12. Onakewhor JUE, Offor E, Okonofua FE. Maternal and neonatal seroprevalence of Hepatitis B surface antigen ( $\mathrm{HBsAg}$ ) in Benin City. J Obstet Gynaecol 2001;21:5836.

13. Akani CI, Ojule AC, Opurum HC, Ejilemele AA. Seroprevalence of HBsAg in pregnant women in Port Harcourt. Nigeria. Niger Postgrad Med J 2005;12:266-70.

14. Obi RK, Umeh SC, Okurede $\mathrm{OH}$. Prevalence of hepatitis B virus infection among Pregnant women in an antenatal clinic in Port Harcourt, Nigeria. Afr J Clin Exp Micro 2006;7:78-82.

15. Agbede 00, Iseniyi J0, Kolawole MO, Ojuowa A. Risk factors and seroprevalence of hepatitis B surface antigenemia in mothers and their preschool age children in Ilorin, Nigeria. Therapy 2007;4:67-72.

16. Awole M, Gebre-Selassie S. Seroprevalence of hepatitis B surface antigen and its risk factors among pregnant women in Jimma, Southwest Ethiopia. Ethiop J Health Develop 2005;19:45-50.

17. Zali MR, Mohammed K, Farhadi A, et al. Epidemiology of hepatitis B in the Islamic Republic of Iran. East Mediterr Health J 1996;2:290-9.

18. Abdool-Karim SS, Thejpal R, Singh B. High prevalence of hepatitis B infection in rural black adults in Mseleni, South Africa. Am J Publ Health 1989;79:893-4.

19 Kao,J.H and Chen,D.S Global control of Hepatitis B Virus infection Lancet 2002,2;395-403. 